\title{
Conservation goals for the Cape mountain zebra Equus zebra zebra-security in numbers?
}

\author{
Halszka Hrabar and Graham I. H. Kerley
}

\begin{abstract}
The target of the 2002 IUCN Action Plan for the Cape mountain zebra Equus zebra zebra was for a population of 2,500 animals. We assessed the validity of this goal by reviewing the conservation status of the subspecies and the prospects of achieving larger populations. All subpopulations were identified and data on each were collected by means of a questionnaire survey. The total extant Cape mountain zebra population was found to consist of at least 2,790 individuals in 52 subpopulations. The target number of 2,500 has therefore been exceeded and this success is largely attributable to the private sector, as there are at present double the number of privately owned subpopulations (35) compared to formally protected subpopulations (17) and the percentage of the population on privately owned land rose from $14 \%$ in 1998 to $32 \%$ in 2009 . The security of the subspecies is still of concern, however, as the growing proportion of the metapopulation on private land is more vulnerable to threats associated with small populations and management actions. The total existing area available to the Cape mountain zebra is $>935,191$ ha and it could potentially support a considerably larger population. We conclude that the IUCN target is substantially below the potential for recovery of the Cape mountain zebra and we recommend this target be revised in the light of these findings. More comprehensive conservation strategies to address current and potential future threats are also needed.
\end{abstract}

Keywords Available habitat, Cape mountain zebra, Equus zebra zebra, minimum viable population, private owners, South Africa, threats

\section{Introduction}

Conservation targets are invariably a compromise between the theory-based ideals that would ensure the persistence of a species or population and the reality of the constraints of resources and opportunity (Margules \& Pressey, 2000). Ideally, targets should be driven by the commitment to the persistence of a species, which should inform decision-makers as to the resource investment

HalszKa Hrabar (Corresponding author) and Graham I. H. Kerley Centre for African Conservation Ecology, Department of Zoology, Nelson Mandela Metropolitan University, PO Box 77000, Port Elizabeth 6031, South Africa. E-mail halszka.hrabar@live.nmmu.ac.za

Received 21 July 2011. Revision requested 16 September 2011.

Accepted 13 December 2011. required to achieve the conservation objectives. However, such compromised targets may also be influenced by a poor understanding of the needs of a species for survival, as well as underestimation of the potential to achieve larger, more reliable, conservation targets. An example of the former is where conservation targets for many large mammal species have been set based on earlier estimates of minimum viable populations with an effective population size of c. 500 (e.g. Lande \& Barrowclough, 1987; Armbruster \& Lande, 1993). This figure of 500 is, however, based on maintaining genetic variation in leg hair patterns in fruit flies and is 30 years old (Franklin, 1980) and outdated. Recent estimates have been consistently higher than this (Reed et al., 2003). Traill et al. (2007), for example, showed the median minimum viable population for mammals should be $>4,000$ breeding individuals. An example of the underestimation of conservation potential is where land-use changes or policies increase the opportunity for conservation, such as the recent burgeoning investment in private nature reserves in South Africa (Sims-Castley et al., 2006). It is therefore clear that the revision of conservation targets should be ongoing, with a view to maximising the potential for species' survival. Here we review the conservation status of the Cape mountain zebra Equus zebra zebra in the context of the accepted conservation goals for this subspecies, as well as the opportunity to achieve greater and more successful conservation outcomes. We also highlight the key role that private land ownership may have in the preservation of this subspecies.

Recent genetic studies (Moodley \& Harley, 2005) have confirmed the validity of the subspecies-focused conservation efforts for the Cape mountain zebra. Endemic to South Africa, they were once widespread in the mountains of the Western and Eastern Cape Provinces (Millar, 1970a, b; Fig. 1). Excessive hunting and habitat loss to agriculture, however, left their numbers in a critical state in the 1950s, with $<80$ individuals remaining in only three relic populations. One of these populations, formally protected (i.e. on government land) in the Mountain Zebra National Park since 1937, consisted of 19 individuals at the time, and the Kammanassie Nature Reserve and Gamka Nature Reserve populations consisted of no more than five and six individuals at their respective nadirs (Millar, 1970a; Lloyd, 1984).

Since the 1950 s the number of Cape mountain zebras has gradually increased through active conservation programmes, with a metapopulation approach through translocations to ensure continued population growth and genetic diversity (Novellie et al., 2002). By 2002 the 


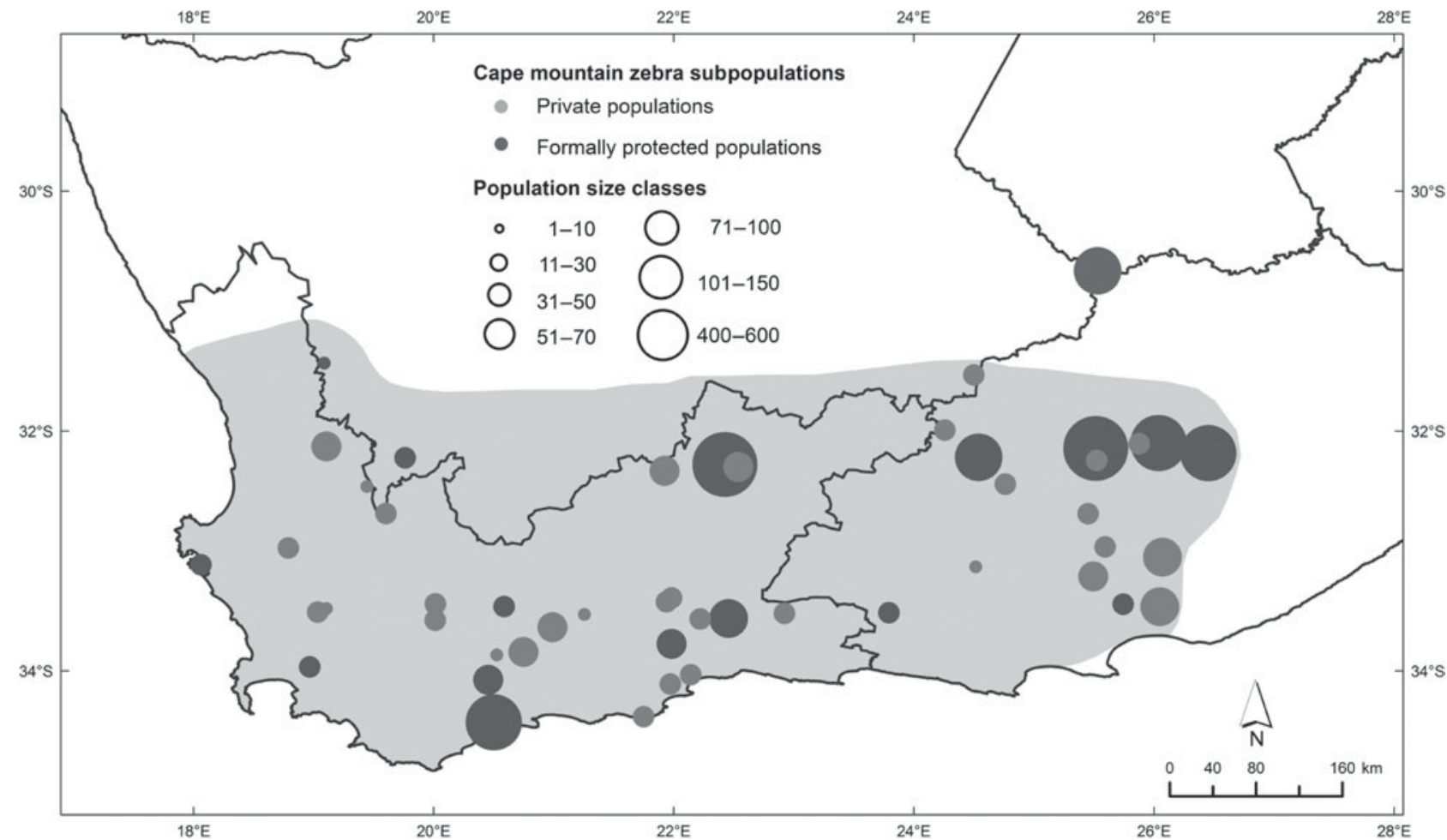

FIG. 1 Approximate historical (shaded region; Novellie et al., 2002) and current distribution of all privately owned (as identified in this study) and formally protected Cape mountain zebra Equus zebra zebra subpopulations in South Africa.

Cape mountain zebra population totalled $>1,600$ individuals in six national parks, 10 provincial reserves and 17 private reserves distributed across most of their natural range (Castley et al., 2002). This suggested that strategies to conserve the Cape mountain zebra, categorized as Vulnerable on the IUCN Red List (Novellie, 2008), were on track to achieve the objective of the IUCN Action Plan to 'build up numbers to a target of 2,500 as quickly as possible' (Novellie et al., 2002). Kerley et al. (2003) showed that the subspecies also serves as a key umbrella taxon in a conservation plan for the Cape Floristic Region, being a large mammal endemic to the area. Privately owned land has played a crucial role in the conservation of the Cape mountain zebra from as far back as the 1930s when the last few groups in the Cradock area were saved from extinction by local farmers (Skead, 2011). This population was formally protected in 1937 by the proclamation of the Mountain Zebra National Park, which was expanded in 1964 permitting the further incorporation of a number of mountain zebra groups occurring on neighbouring private farms (Penzhorn, 1975). The subsequent increase of this population enabled the translocation of individuals to 25 other protected areas during the 1980 s and early 1990s, a number of which were private game ranches (Novellie et al., 2002). Subpopulations maintained by private landowners have since increased considerably and by the late 1990s sales from the private sector were possible. Private populations have, however, been poorly monitored in recent years and the contribution of the private sector towards conservation efforts was previously unknown.

We carried out a survey to determine (1) the extant population size, (2) the contribution of the private sector towards the conservation of the Cape mountain zebra, (3) threats to the subspecies, and (4) future conservation prospects. We use these findings to evaluate the currently accepted IUCN conservation target of 2,500 individuals, highlight the role of private ownership for conservation of the Cape mountain zebra, and identify the need to understand the role of predation and hunting on the conservation strategy for the subspecies.

\section{Methods}

We first identified private owners of Cape mountain zebras from permit records and through contacts with individuals involved in conservation within the distribution area of the Cape mountain zebra (Millar, 1970a). Formally protected populations were identified through the species lists of reserves. A questionnaire was sent to all owners regarding the current and historical details of each subpopulation (numbers, deaths, translocations and population growth data), property size and location, presence of predators, records of predation events, interest in hunting of the Cape mountain zebra, and ownership motivation. A basic indication of population performance was required: 'good' 
if the population had increased since reintroduction, 'stable' if it had remained unchanged, and 'poor' if there had been a decrease in numbers. Ownership motivation enquiries included (1) whether Cape mountain zebras were considered an asset to the property, (2) whether there was an interest in purchasing more, and (3) the reasons for owning the species.

Questionnaires were completed in direct interviews with as many owners as possible, to ensure a clear understanding of the questions and answers. Similar data were retrieved for subpopulations on formally protected land (provincial reserves and national parks). $t$-tests were used to test for differences between private and public populations/properties (Zar, 1999).

\section{Results}

A total of 52 Cape mountain zebra subpopulations were identified. There is now double the number of privately owned populations (35) compared to formally protected populations (17; Fig. 1). The number of privately owned subpopulations has doubled since 2002, whereas there is only one additional formally protected population (Fig. 2; Table 1).

The total extant Cape mountain zebra population was found to consist of at least 2,790 individuals (count data from one known private population were unobtainable) and the average annual rate of increase in population size between 2002 and 2009 was $10.6 \%$ (Fig. 3). The majority $(68 \%)$ of individuals are on formally protected land (despite the larger number of privately owned subpopulations) and the mean size of formally protected populations was significantly larger than privately owned populations $(t=2.94$, $\mathrm{df}=49, \mathrm{P}<0.01$; Table 1). For example, the Mountain Zebra National Park and Karoo National Park subpopulations alone made up 22 and $18 \%$, respectively, of the population. The percentage of the population on privately owned land has, however, risen from $14 \%$ in 1998 to $32 \%$ (Fig. 3). Two extralimital populations occur in Gariep Nature Reserve in the Northern Cape (Fig. 1) and in the West Coast National Park, which is c. $70 \mathrm{~km}$ from the closest historically-recorded Cape mountain zebra population in the Piketberg (Skead, 2011).

We found that the total area available to the Cape mountain zebra is $>291,881$ ha on private land (the sizes of two private properties were not obtainable) and 643,310 ha on formally protected land; i.e. a total of 935,191 ha. Formally protected properties were significantly larger (Table 1 ) than privately owned areas $(t=3.264, \mathrm{df}=47, \mathrm{P}<0.01)$, yet zebra density was not significantly different between the two property types $(t=0.360, \mathrm{df}=47, \mathrm{P}=0.721$; Table 1$)$.

Thirty-six questionnaires were completed $(22$ by private land owners). From these, the performance of
TABLE 1 A comparison between privately owned and formally protected Cape mountain zebra Equus zebra zebra subpopulations.

\begin{tabular}{|c|c|c|}
\hline & Privately owned & Formally protected \\
\hline No. of populations & 35 & 17 \\
\hline Total no. of individuals & 902 & 1,888 \\
\hline $\begin{array}{l}\text { Mean population } \\
\text { size } \pm S D\end{array}$ & $\begin{array}{l}27 \pm 19 \\
(\mathrm{n}=34)\end{array}$ & $\begin{array}{r}111 \pm 167 \\
(\mathrm{n}=17)\end{array}$ \\
\hline Population size range & $4-65$ & $3-596$ \\
\hline $\begin{array}{l}\text { Total land area } \\
\text { available (ha) }\end{array}$ & $>291,881^{1}$ & 643,310 \\
\hline $\begin{array}{l}\text { Mean property } \\
\text { size } \pm S D(h a)^{2}\end{array}$ & $\begin{array}{l}9,115 \pm 11,181 \\
(\mathrm{n}=32)\end{array}$ & $\begin{array}{l}37,842 \pm 47,787 \\
(\mathrm{n}=17)\end{array}$ \\
\hline Property size range $(\mathrm{ha})^{2}$ & $1,100-54,000$ & $1,800-180,000$ \\
\hline $\begin{array}{l}\text { Mean zebra } \\
\text { density }\left(\mathrm{ha}^{-1}\right)^{2}\end{array}$ & $\begin{array}{l}0.006 \pm 0.007 \\
(\mathrm{n}=32)\end{array}$ & $\begin{array}{l}0.007 \pm 0.008 \\
(\mathrm{n}=17)\end{array}$ \\
\hline
\end{tabular}

${ }^{1}$ Excludes two properties for which area data are not available ${ }^{2}$ Excludes one population kept on cultivated fields

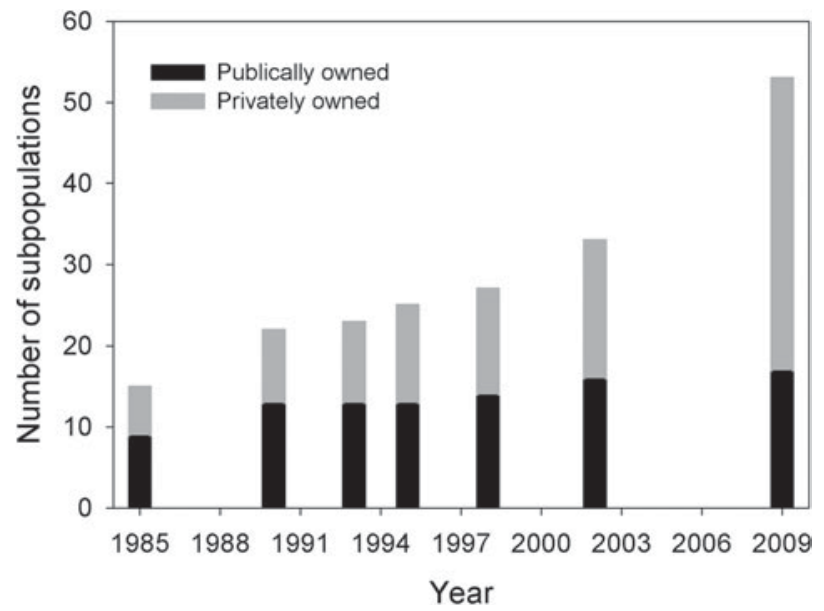

FIG. 2 The total number of Cape mountain zebra subpopulations on privately owned and formally protected land in South Africa from 1985-2009 (data for 1985-1998 from Novellie et al. (2002), and 2002 data from Castley et al. (2002).

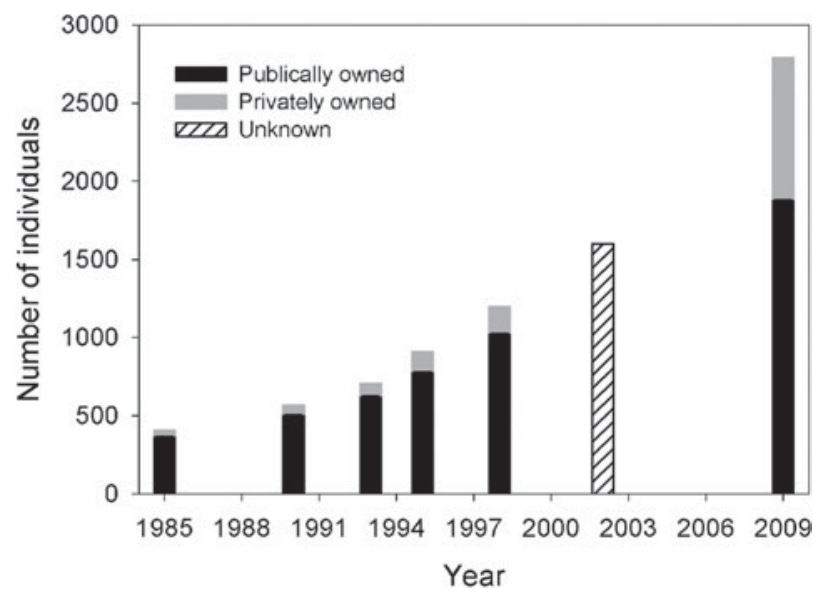

FIG. 3 The total number of Cape mountain zebras on privately owned and formally protected land in South Africa from 1985-2009 (data for 1985-1998 from Novellie et al. (2002), and 2002 data from Castley et al., 2002). 
27 populations ( 11 formally protected and 16 private) was reported as good, six were stable (two formally protected and four private) and three had decreased in size (two formally protected and one private). One population with poor performance was subjected to drought conditions soon after release, and one suffered from poaching and emigration. Ten of the 52 subpopulations have fewer than the recommended 14 animals (Novellie et al., 1996) and eight of these are privately owned (four of which have not increased in size despite being more than 10 years old). Additionally, six out of 22 privately owned populations (only those with appropriate data included) have only had a single introduction event.

The lion Panthera leo has been reintroduced into two privately owned areas that have Cape mountain zebra (in 2003 and 2007) as well as into the Karoo National Park (in 2010). Cheetahs Acinonyx jubatus have been reintroduced into the area of four subpopulations (between 2004 and 2007). Predation reports from the survey are limited to a single lion kill of an adult in a private population, and at least five kills by lions in the Karoo National Park (Craig Tambling, pers. comm.). One leopard Panthera pardus kill of a foal was reported but no cheetah kills.

Attitudes of private owners towards Cape mountain zebra were positive and 20 out of 22 private owners considered them as an asset to their property. Only 10 owners were interested in purchasing more, however, because many of the populations were considered to be near carrying capacity. The most common motivation for owning Cape mountain zebras (owners could have more than one reason) was for the conservation of the subspecies (20 owners). Twelve owners aimed to breed Cape mountain zebra for sale and/or have owned them for their tourism value. Only five owners were interested in hunting the Cape mountain zebra.

\section{Discussion}

Efforts to conserve the Cape mountain zebra have so far been a success, to the extent that the extant population exceeds the target size of 2,500 individuals set by the 2002 IUCN Action Plan (Novellie et al., 2002) and is now a minimum of 2,790 animals. Population growth has also continued to remain positive, as the mean annual rate of increase was maintained at 10\% between 2002 and 2009, compared to $8.6 \%$ from 1985 to 1995 (Novellie et al., 1996), 9.6\% between 1995 and 1998 (Novellie et al., 2002) and 8.4\% between 1998 and 2002. Given the fact that most populations are recently founded, and new populations are being added, it is highly likely that the Cape mountain zebra has the potential to reach about double the current number. It is therefore clear that the IUCN target set in 2002 was substantially below the potential for in situ Cape mountain zebra conservation, as well as being well below current estimates of minimum viable populations for large mammals (Traill et al., 2007). Given that mature individuals make up about one third of wild equid populations (e.g. Gobi khulan Equus hemionus; Feh et al., 2001) and that the minimum viable population (breeding individuals) for large mammals is c. 4,000 (Traill et al., 2007), a more appropriate target population size could potentially be as large as 12,000 individuals. A minimum viable population therefore needs to be identified for Cape mountain zebra and the target population size revised.

The successful growth of the Cape mountain zebra population is attributable to two key factors: (1) the metapopulation approach to the management of the subspecies, and (2) the increase in available habitat. The expansion of formally protected areas such as the Mountain Zebra and Karoo National Parks, which have increased from 6,536 and 41,000 ha to 28,412 and 88,122 ha, respectively, has allowed the further expansion of the two largest subpopulations. Most notable, however, is the crucial role the private sector has played in increasing the available habitat and the distribution of the Cape mountain zebra within its range, doubling the number of subpopulations in the last decade. Additionally, private owners are becoming increasingly important in purchasing available animals from existing subpopulations, thereby ensuring continued growth of these populations by reducing density dependent effects (as observed in the De Hoop population, Smith et al., 2007). A further benefit of privately owned populations is that management of these areas is often aimed at achieving maximum population growth rates (through promoting grassland for Cape mountain zebra, for example; Smith et al., 2011; Faith, 2012), whereas management of formally protected areas needs to focus on conserving the natural habitat and its biodiversity. Given the role of the number of subpopulations in the persistence of a metapopulation (Hanski, 1991) the increase in the number of subpopulations contributes substantially to the conservation of this subspecies.

Although the status of the Cape mountain zebra has clearly improved, the long-term security of the subspecies is, however, still uncertain. The majority of the metapopulation currently lives on formally protected land (which is vital, according to Novellie et al., 2002), yet the third of the metapopulation on privately owned land could be at risk for a number of reasons. Of primary concern is the small size of many privately owned subpopulations. Novellie et al. (1996) noted the wasted effort in introducing an excessively small number of founder individuals, as this tends to result in either a failed reintroduction or poor population performance in the long term (see also Komers \& Curman, 2000). Our survey confirmed this effect on demographics, as four out of six subpopulations that have not increased since their introduction had founder populations of $<14$ individuals. This may be a result of a form of the Allee effect, in which 
reproduction is enhanced by conspecific competition between males (Stephens et al., 1999). Inbreeding depression and genetic drift is a second threat associated with small populations (Frankham, 1996), and susceptibility to diseases such as equine sarcoids is greater in inbred populations (Sasidharan, 2006; Sasidharan et al., 2011). The IUCN Action Plan (Novellie et al., 2002) recommended that one or two animals be added to subpopulations once every $5-10$ years to avoid inbreeding depression, yet neither this nor the advice for a minimum founder population of 14 individuals has been adhered to because of the cost of investing in a large number of animals (pers. comms with private land owners).

Furthermore, most of the metapopulation is at risk of inbreeding because all reintroduced subpopulations except for that in De Hoop Nature Reserve originate from only one of the natural relic populations (in Mountain Zebra National Park). Two thirds of the entire genotype is therefore located in just two populations, both of which are at risk because of limited habitat availability. Even though numbers exhibit a positive trend, the subspecies cannot be considered secure until the full genetic diversity is conserved and represented throughout the metapopulation. Another factor that could affect demographics and genetic diversity of privately owned subpopulations in the future is hunting (Lloyd \& Rasa, 1989; Milner et al., 2006). Although owners expressed little interest in hunting Cape mountain zebra, if the current ban on imports of Cape mountain zebra trophies into the USA is lifted, this could change. The effect could be two-fold: (1) the demand for the Cape mountain zebra by private land owners may increase because of the rise in their value, thereby increasing the number of subpopulations still further; (2) hunting of selected individuals in small populations could have a significant negative effect on this socially complex species; e.g. removal of bachelor males would prevent the formation of new breeding herds with new genetic input (Lloyd \& Rasa, 1989).

The potential loss of genetic integrity through hybridization between the plains zebra Equus burchelli and Cape mountain zebra needs to be considered. Hybridization is more likely to occur in poor habitats or small populations, where low mate availability and skewed sex ratios may lead to exclusion of some individuals from mating (Mace \& Waller, 1998; Jansson et al., 2007), which is the case for a number of Cape mountain zebra populations. A horse Equus ferus $\mathrm{x}$ Cape mountain zebra hybrid has been reported in De Hoop Nature Reserve, for example, where a bias towards adult male Cape mountain zebra exists (i.e. significantly more males than the expected $1: 1$ sex ratio; Peter Lloyd, pers. comm.). Hybridization within the genus Equus is well documented and even occurs between two wild equid species with naturally overlapping distributions (plains zebra and Grevy's zebra Equus grevyi; Cordingley et al., 2009). The occurrence of this hybridization in the Laikipia ecosystem of northern Kenya may be because of the skewed sex ratio in favour of males within Grevy's zebra and the numerical dominance of plains zebra in the region (Cordingley et al., 2009). Hartmann's mountain zebra Equus zebra hartmannae $\mathrm{x}$ plains zebra hybrids have also been reported (unconfirmed genetically) in the wild in Etosha National Park (Oliver Ryder, pers. comm.). There are, however, no records of Cape mountain zebra x plains zebra hybrids that we are aware of, although the two species are sympatric in five areas. Hybridization with plains zebra as a threat to Cape mountain zebra populations is not of great concern, as fertile hybrids are unlikely because of the large difference in the number of chromosome pairs between the two species ( 44 vs 32 in plains zebra and Cape mountain zebra, respectively). Grevy's zebra and plains zebra, which do produce fertile hybrids, have a more similar number of chromosome pairs (46 vs 44 respectively; Ryder et al., 1978; Cordingley et al., 2009).

Further potential threats to the Cape mountain zebra include predation, poaching and emigration. Poaching and emigration (facilitated by poor fencing and fence-cutting) have already had a negative impact on one formally protected population, which decreased from 143 individuals in 2002 to 102 in 2009.

The predation environment for Cape mountain zebra has changed in the last decade. Previously, predation would have been by leopards, which are present at low (but unknown) densities in many localities where there are Cape mountain zebras. Four populations are, however, now exposed to cheetahs and three to lions, and the second largest population, in the Karoo National Park, is one of the populations now exposed to lions (since 2010). There are no known cases of foals being killed by leopards or cheetahs and because of the Cape mountain zebra's relatively large body weight $(203-260 \mathrm{~kg})$ lions are the only predator to pose a real threat to adults (Mills \& Hes, 1997; Hayward \& Kerley, 2005; Hayward et al., 2006; Owen-Smith \& Mills, 2008). Predation pressure is therefore still minimal.

Predation could restore a facet of natural selection, thereby causing a healthy improvement in Cape Mountain Zebra populations, yet the impact on numbers could still be negative. Exposure to predators has substantial behavioural implications, as shown by the impact of wolf Canis lupus reintroduction on ungulates in the Yellowstone system (Ripple \& Beschta, 2004). Thus the reintroduction of predators can be expected to substantially alter the resource use and demographics of the Cape mountain zebra, and this needs to be taken into account in the conservation planning for this subspecies. We predict that Cape mountain zebra populations exposed to predators will have decreased growth rates and lower overall densities.

In conclusion, targets for the conservation of the Cape mountain zebra clearly need to be reassessed, as the previous target of 2,500 individuals is well below estimates of the minimum viable population and also well below the 
population potential for in situ conservation of the Cape mountain zebra. High numbers alone may not be sufficient to ensure the security of this subspecies, or other threatened species. Conservation of the full range of genetic diversity also needs to be a priority (i.e. including genes from the two 'unutilized' relic subpopulations into the rest of the metapopulation), as well as ensuring threats associated with small populations (common in metapopulations) are minimized. The effective population size (i.e. number of breeding individuals) in subpopulations and the entire metapopulation is also an important contributing factor to a species' survival, yet this is still not known for the Cape mountain zebra. The increasing role of private landowners in conservation in South Africa is evident, together with the problems associated with private ownership, such as control of management actions such as hunting.

We recommend that conservation efforts for the Cape mountain zebra should now include: (1) increasing the size of existing small subpopulations, (2) ensuring the genetic diversity of subpopulations, (3) gaining a better understanding of the effect of hunting and predation on demographics, (4) determining the effective population size in subpopulations and the metapopulation, (5) determining the potential population size for the available habitat, and (6) identifying the minimum viable population size. With such efforts, together with the continued increase in habitat availability (capable of supporting 7,000 adults; Reed et al., 2003), the chances for the long-term conservation of the subspecies would be greatly enhanced.

These recommendations have been passed on to the appropriate authorities and private land owners are now able to access current Cape mountain zebra management recommendations and general information from a website dedicated to the subspecies. The above-mentioned six recommendations have become a priority for research, and the results from this study will be included in the next management plan for the species.

\section{Acknowledgements}

This survey was funded by the Professional Hunters Association of South Africa. The authors thank all the reserve owners and managers who took the time to complete the questionnaire and to $\mathrm{O}$. Huyser for his input.

\section{References}

Armbruster, P. \& Lande, R. (1993) A population viability analysis for African elephant (Loxodonta africana): how big should reserves be? Conservation Biology, 7, 602-610.

Castley, G., Lloyd, P.H. \& Moodley, Y. (2002) Cape Mountain Zebra, Equus zebra zebra Taxon Data Sheet. IUCN Conservation Assessment Management Plan, Randburg, South Africa.
Cordingley, J.E., Sundaresan, S.R., Fischhoff, I.R., Shapiro, B., Ruskey, J. \& Rubenstein, D.I. (2009) Is the endangered Grevy's zebra threatened by hybridization? Animal Conservation, 12, 505-513.

FAith, J.T. (2012) Palaeozoological insights into management options for a threatened mammal: southern Africa's Cape mountain zebra (Equus zebra zebra). Diversity and Distributions, 18, 438-447.

Fen, C., Munkhtuya, B., Enkhbold, S. \& Sukhbaatar, T. (2001) Ecology and social structure of the Gobi Khulan Equus hemionus subsp. in the Gobi B National Park, Mongolia. Biological Conservation, 101, 51-61.

Frankham, R. (1996) Relationship of genetic variation to population size in wildlife. Conservation Biology, 10, 1500-1508.

FRANKLIN, I.R. (1980) Evolutionary change in small populations. In Conservation Biology: An Evolutionary-Ecological Perspective (eds M.E. Soule \& B.A. Wilcox), pp. 135-149. Sinauer, Sunderland, USA.

HANSKI, I. (1991) Single species metapopulation dynamics: concepts, models and observations. Biological Journal of the Linnean Society, $42,3-16$.

Hayward, M.W., Henschel, P., O’Brien, J., Hofmeyr, M., Balme, G. \& Kerley, G.I.H. (2006) Prey preferences of the leopard (Panthera pardus). Journal of Zoology, 270, 298-313.

Hayward, M.W. \& Kerley, G.I.H. (2005) Prey preference in the lion. Journal of Zoology, 267, 309-322.

Jansson, G., Thulin, C.G. \& Pehrson, A. (2007) Factors related to the occurrence of hybrids between brown hares Lepus europaeus and mountain hares L. timidus in Sweden. Ecography, 30, 709-715.

Kerley, G.I.H., Pressey, R.L., Cowling, R.M., Bosshoff, R.M. \& Sims-Castley, R. (2003) Options for the conservation of large and medium-sized mammals in the Cape Floristic Region hotspot, South Africa. Biological Conservation, 112, 169-190.

Komers, P.E. \& Curman, G.P. (2000) The effect of demographic characteristics on the success of ungulate re-introductions. Biological Conservation, 93, 187-193.

Lande, R. \& Barrowclough, G.F. (1987) Effective population size, genetic variation, and their use in population management. In Viable Populations for Conservation (ed. M.E. Soule), pp. 87-123. Cambridge University Press, Cambridge, UK.

Lloyd, P.H. (1984) The Cape mountain zebra 1984. African Wildlife, $38,144-149$.

Lloyd, P.H. \& RASA, O.A.E. (1989) Status, reproductive success and fitness in Cape mountain zebra (Equus zebra zebra). Behavioral Ecology and Sociobiology, 25, 411-420.

MACE, R.D. \& W Aller, J.S. (1998) Demography and population trend of grizzly bears in the Swan Mountains, Montana. Conservation Biology, 12, 1005-1016.

Margules, C.R. \& Pressey, R.L. (2000) Systematic conservation planning. Nature, 405, 243-253.

Millar, J.C.G. (1970a) Census of Cape mountain zebra: part I. African Wildlife, 24, 17-25.

Millar, J.C.G. (1970b) Census of Cape mountain zebra: part II. African Wildlife, 24, 105-114.

Mills, G. \& Hes, L. (eds) (1997) The Complete Book of Southern African Mammals, 1st edition. Struik Publishers, Cape Town, South Africa.

Milner, J.M., Nilsen, E.B. \& Andreassen, H.P. (2006) Demographic side effects of selective hunting in ungulates and carnivores. Conservation Biology, 21, 36-47.

Moodley, Y. \& Harley, E.H. (2005) Population structuring in mountain zebras (Equus zebra): the molecular consequences of divergent demographic histories. Conservation Genetics, 6, 953-968.

Novellie, P. (2008) Equus zebra ssp. zebra. In IUCN Red List of Threatened Species v. 2012.2. Http://www.iucnredlist.org [accessed 21 November 2012]. 
Novellie, P., Lindeque, M., Lindeque, P., Lloyd, P. \& Koen, J. (2002) Status and Action Plan for the Mountain Zebra (Equus zebra). In Equids: Zebras, Asses and Horses: Status, Survey and Conservation Action Plan (ed. P. Moehlman), pp. 28-42. IUCN, Gland, Switzerland.

Novellie, P.A., Millar, P.S. \& Lloyd, P.H. (1996) The use of VORTEX simulation models in a long term programme of reintroduction of an endangered large mammal, the Cape mountain zebra (Equus zebra zebra). Acta Oecologica, 17, 657-671.

Owen-Smith, N. \& Mills, M.G.L. (2008) Predator-prey size relationships in an African large-mammal food web. Journal of Animal Ecology, 77, 173-183.

Penzhorn, B.L. (1975) Behaviour and population ecology of the Cape Mountain Zebra Equus zebra zebra Linn., 1758 in the Mountain Zebra National Park. PhD thesis. University of Pretoria, Pretoria, South Africa.

Reed, D.H., O’Grady, J.J., Brook, B.W., Ballou, J.D. \& Frankham, R. (2003) Estimates of minimum viable population sizes for vertebrates and factors influencing those estimates. Biological Conservation, 113, 23-34.

Ripple, W.R. \& Beschta, R.L. (2004) Wolves and the ecology of fear: can predation risk structure ecosystems? Bioscience, 54, 755-766.

SAsidharan, S.P. (2006) Sarcoid tumours in Cape mountain zebra (Equus zebra zebra) populations in South Africa: a review of associated epidemiology, virology and genetics. Transactions of the Royal Society of South Africa, 61, 11-18.

Sasidharan, S.P., Ludwig, A., Harper, C., Moodley, Y., Bertschinger, H.J. \& Guthrie, A.J. (2011) Comparative genetics of sarcoid tumour-affected and non-affected mountain zebra (Equus zebra) populations. South African Journal of Wildlife Research, 41, $36-49$.

Ryder, O.A., Epel, N.C. \& Benirschke, K. (1978) Chromosome banding studies of the Equidae. Cytogenet. Cell Genetics, 20, $332-350$.

Sims-Castley, R., Kerley, G.I.H., Geach, B.G.S. \& Langholz, J. (2006) The Socio-economic significance of eco tourism-based private game reserves in South Africa's Eastern Cape Province. Parks, 15, 6-18.

SKEAD, C.J. (2011) Historical Incidence of the Larger Land Mammals in the Broader Eastern Cape. 2nd edition. (eds A. Boshoff, G.I.H. Kerley \& P. Lloyd). Centre for African Conservation Ecology, Nelson Mandela Metropolitan University, Port Elizabeth, South Africa.

Smith, R.K., Marais, A., Chadwick, P., Lloyd, P.H. \& Hill, R.A. (2007) Monitoring and management of the endangered Cape mountain zebra Equus zebra zebra in the Western Cape, South Africa. African Journal of Ecology, 46, 207-213.

Smith, R.K., Ryan, E., Morley, E. \& Hill, R.A. (2011) Resolving management conflicts for an endangered species in a habitat classified as a World Heritage Site? Environmental Conservation, $38,325-333$.

Stephens, P.A., Sutherland, W.J. \& Freckleton, R.P. (1999) What is the Allee effect? Oikos, 87, 185-190.

Traill, L.W., Corey Bradshaw, J.A. \& Brook, B.W. (2007) Minimum viable population size: a meta-analysis of 30 years of published estimates. Biological Conservation, 139, 159-166.

ZAR, J.H. (1999) Biostatistical Analysis. 4th edition. Prentice-Hall, Englewood Cliffs, USA.

\section{Biographical sketches}

HALSZKA HRABAR's research interests include plant-herbivore interactions and population dynamics of large mammals, including sex ratios at birth. Her research on zebras began in the Serengeti, Tanzania, and is now focused on conservation issues for the Cape mountain zebra in South Africa. Grah a M KerLey is Director of the Centre for African Conservation Ecology at the Nelson Mandela Metropolitan University and a member of the Board of South African National Parks. His research interests focus on conservation biology and the consequences of resource use by large herbivores and predators. 